\title{
Design and Implementation of Pneumatic Gear Shifting Mechanism for Shifter Kart
}

\author{
Bansode Lawrence \\ Department of Instrumentation Engineering. \\ Pravara Rural Engineering College. \\ Loni, India
}

\author{
Ghorpade Pradumnya \\ Department of Mechanical Engineering. \\ Pravara Rural Engineering College. \\ Loni, India
}

\begin{abstract}
In this paper Design scheme of Pneumatic gear shifting mechanism for a shifter kart has been introduced. Shifter karts are included in open wheel, four wheeled racing categories with usually no suspension. Performance comparison is done between manual and pneumatic shifting mechanism based on basic criteria's like shifting time, driver safety, weight of the system and complexity of the system. Results depict pneumatic shifting mechanism counts more pros over traditional shifting mechanism in various aspects of performance.
\end{abstract}

Keywords - Shifter kart; pneumatic; compressor; DCV; reservior;

\section{INTRODUCTION}

A lot of innovation work has already been done in the Commercial automobile sector regarding safety, driver comfort and many other features since decades. Competitive racing on other hand focuses mainly on innovations which cut down lap times and ups the endurance and efficiency. It includes traction control, ABS (Anti-Lock Braking System), electronically adjustable suspension and so on. Therefore, many core automobile manufacturers have their racing teams available from which they can borrow technology and implement it in their commercial production automobiles. One place where all racers start their carriers in some point of time is karting [1]. It is an open wheel, four wheeled racing categories with usually no suspension. It consists of three main subcategories sprint, endurance and speedway. It is considered the first step in racing due to its very own raw nature. Unlike F1 or any other category where there are plenty of aids that assist the driver while gulping lap after lap. In karting however there are no driving aids assisting you. No traction control, no suspension, no power steering, no ABS and so on. It's just the driver and the raw power from the engine and is therefore considered a very good platform to brush up driving skills and new technology at cheap. Since, karts have a one to one steering ratio, short wheelbase and usually do $160 \mathrm{mph}$ while racing it is quite unsafe to shift gears with one hand. While, only the other hand on the steering wheel.

Many researchers have tried to elucidate this problem by implementing pneumatic or electronic shifting mechanism.

In [2] pneumatic shifting mechanism is introduced based on microcontroller and two double acting cylinders. A new strategy to shift gears has been introduced in [3] using stepper motors. Also [4] has implemented use of PLC and double acting cylinder for shifting mechanism. In [5] electro pneumatic system has been implemented using relays to shift gears. In [6] arduino has been used as controller. Reference [7] discusses electronic shift system. Electro pneumatic shift system has been discussed for sequential gearbox in [8]. Also [9] shows design of electro pneumatic gear and clutch actuation for formula SAE sequential gearbox. Mostly pneumatic system is preferred over hydraulic and electronic system due its various traits like speed of response and complexity. But is usually limited by Availability of onboard supply of compressed air. The design scheme introduced in this paper eliminates the problem.

The rest of the paper is arranged as follows. Section 2 depicts component selection and design. Section 3 shows Working of the system. Results are discussed in section 4. And section 5 concludes the paper.

\section{COMPONENT SELECTION AND DESIGN}

\section{A. List of components}

TABLE I: List of components

\begin{tabular}{|c|c|c|c|}
\hline \multirow{2}{*}{ Sr.no } & \multicolumn{3}{|c|}{ Table } \\
\hline & Component & Specifications & $\begin{array}{l}\text { Qua } \\
\text { ntity }\end{array}$ \\
\hline 1 & $\begin{array}{l}\text { Pneumatic double acting } \\
\text { cylinder }\end{array}$ & $\begin{array}{l}\text { Bore }=25 \mathrm{~mm} \\
\text { Stroke }=100\end{array}$ & 1 \\
\hline 2 & $3 / 2$ direction control valve & $8 \mathrm{~mm}$ & 2 \\
\hline 3 & DC solenoid valve & $12 \mathrm{~V}$ & 2 \\
\hline 4 & Connectors & $8 \mathrm{~mm}$ & N. A \\
\hline 5 & Pneumatic pipe & $8 \mathrm{~mm}$ & $6 \mathrm{~m}$ \\
\hline 6 & Air reservior & $\begin{array}{c}\text { Height }=465 \mathrm{~mm} \\
\text { Diameter }=139 \mathrm{~mm}\end{array}$ & 1 \\
\hline 7 & Ball valve & $8 \mathrm{~mm}$ & 1 \\
\hline 8 & Presure switch & $\begin{array}{l}0-200 \mathrm{psi} \\
\text { adjustable }\end{array}$ & 1 \\
\hline 9 & Pressure gauge & 0-200 psi & 1 \\
\hline 10 & Non return valve & Ball and spring type & 1 \\
\hline 11 & Air compressor belt type & $10 \mathrm{~s} 11 \mathrm{c}$ & 1 \\
\hline 12 & Belt & 3 pk 0660 & 1 \\
\hline 13 & Push buttons & $10 \mathrm{amp}$ & 2 \\
\hline 14 & Automobile grade wire & multistring & $6 \mathrm{~m}$ \\
\hline 15 & Driving pulley & $\begin{array}{c}\text { 3pk pv3 } \\
\text { Diameter }=100 \mathrm{~mm}\end{array}$ & 1 \\
\hline
\end{tabular}




\section{B. Design details}

In this section cylinder sizing, reservoir design, compressor selection and belt sizing has been discussed. The engine used in this scenario is an YZFR15 engine it has a synchromesh sequential six speed gear box with one down and five up shifting pattern and no false shift problem at all. All the calculations are done on basis of the requirements demanded by the engine.

\section{a) Cylinder design.}

TABLE 2: Cylinder specifications

\begin{tabular}{|l|l|c|c|}
\hline \multirow{2}{*}{ Sr.no } & \multicolumn{3}{|c|}{ Table } \\
\cline { 2 - 4 } & \multicolumn{1}{|c|}{ Description } & Symbol & Values \\
\hline 1 & Pressure Available & P & $60 \mathrm{psi}$ \\
\hline 2 & Force required for shifting & F & $22 \mathrm{lbs}$ \\
\hline 3 & Bore of the piston & B & 0.68 inch \\
\hline 4 & Stroke length & L & 4 inch \\
\hline
\end{tabular}

Assuming we require $22 \mathrm{lbs}$ force for shifting and available pressure is $60 \mathrm{psi}$ the bore of the cylinder can be determined by using the formula

$\mathrm{A}=\mathrm{F} / \mathrm{P}$

$\therefore \mathrm{A}=0.36 \mathrm{sq}$ in

From the area calculated the bore dimensions are calculated $\therefore \mathrm{B}=0.68$ in

\section{b) Reservior and compressor design.}

The reservoir used was an empty fire extinguisher tank which was rated for up to 14 bars of working pressure and can easily withstand the pressure requirements for this applications. The volume of the tank is 7.05 liter weighs $1.5 \mathrm{~kg}$ and has dimensions as mentioned in table 1 .

The compressor used is a car air conditioning system compressor which has following specifications as mentioned in table 3 below.

TABLE 3: Compressor specifications

\begin{tabular}{|l|c|c|}
\hline Sr.no & Parameter & Values \\
\hline 1 & Input power(W) & 900 \\
\hline 2 & Clutch voltage & $12 \mathrm{~V} \mathrm{DC}$ \\
\hline 3 & Type of groove & $3 \mathrm{pk} \mathrm{pv3}$ \\
\hline 4 & Pulley diameter & $115 \mathrm{~mm}$ \\
\hline 5 & Weight & $3 \mathrm{~kg}$ \\
\hline 6 & Flow rate & $51-120 \mathrm{cfm}$ \\
\hline
\end{tabular}

c) Pulley and belt design.

The belt used is a $3 p k$ pv3 V type belt which is 26.66 inch in length and has a top width of 0.4 inches.

The driving pulley is also a $3 \mathrm{pk}$ pv3 pulley with dimensions as mentioned in table 4.
TABLE 4: Belt and pulley specifications

\begin{tabular}{|l|c|c|}
\hline Sr.no & Parameter & Values \\
\hline 1 & Driving pulley diameter & $3.9 \mathrm{in}$ \\
\hline 2 & Driven pulley diameter & $4.5 \mathrm{in}$ \\
\hline 3 & Driving pulley speed & $2000 \mathrm{rpm}$ \\
\hline 4 & Driven pulley speed & $1733 \mathrm{rpm}$ \\
\hline 5 & Center to center distance & $5.5 \mathrm{in}$ \\
\hline 6 & Belt length required & $24 \mathrm{in}$ \\
\hline 7 & Multiplication factor & 0.86 \\
\hline
\end{tabular}

\section{WORKING OF THE SYSTEM}

Shifter karts usually weigh around hundred kilograms and weight play important role in performance. Therefore, system is such designed that it should weigh not more than seven kilograms. Also, electronic control is avoided to reduce chances of failure. Although electronic control improves efficiency it should be only used if it is integrated in the engine control module (ECM)

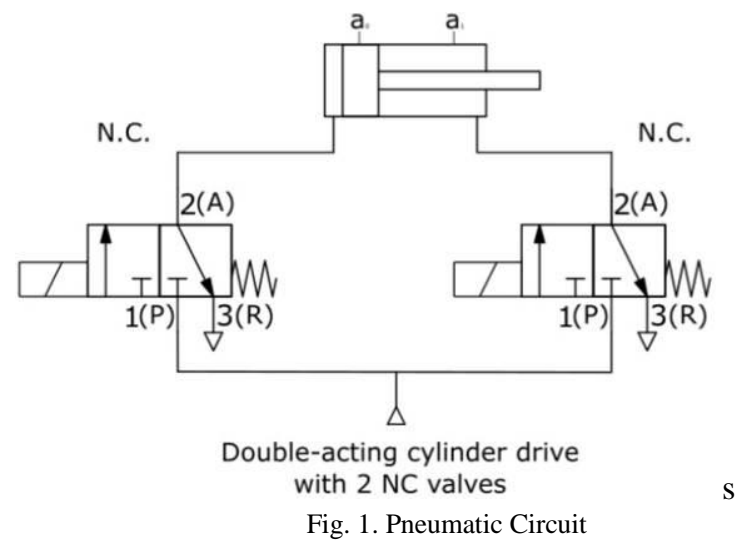

Fig. 1 shows the pneumatic circuit diagram of the system. Two solenoid operated 3/2 DCV are used to control motion of a double acting cylinder. The cylinder is mounted in such a way that $50 \%$ of the throw available is extracted out i.e. half the stroke length is already extracted and the cylinder can extract as well as retract when actuated by either of the DCV. The mechanism built into the gearbox itself brings back the cylinder rod back to its original position after the air is exhausted from the cylinder. The cylinder arrangement is shown in fig. 2. Two buttons mounted on the steering wheel are used to operate the DCV respectively from the karts battery itself, which in turn shifts up or down respectively as shown in fig. 3 . The reservoir is equipped with a non-return valve, pressure switch, pressure gauge, supply valve and a quick relief valve. As shown in fig. 4 the pressure switch is set to 60psi, as soon as the pressure in the reservoir drops below set-point its contact becomes $\mathrm{NC}$ and the clutch on the compressor is engaged and it moves with the shaft via a belt and reservoir pressure starts to build up as soon as the pressure inside the reservoir reaches the set-point the pressure switch trips and its contacts become NO cutting power supply to the compressor clutch and disengages it as shown in fig. 5. When 
the compressor clutch is disengaged the compressor stops rotating and only the clutch pulley rotates with the shaft. The non-return valve prevents the air going back to the compressor. The air pressure can be monitored visually the gauge mounted on the reservoir.
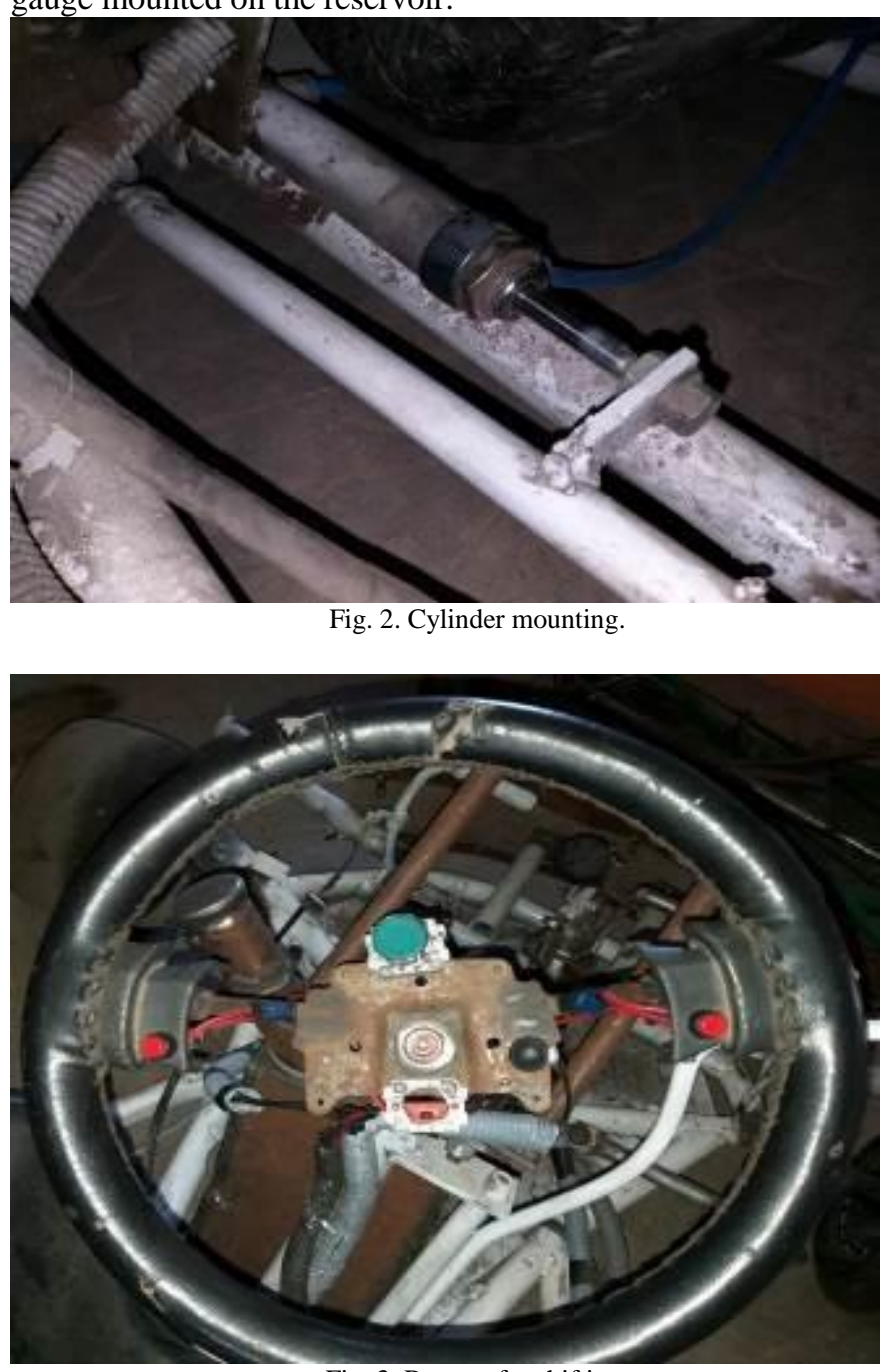

Fig. 3. Buttons for shifting.

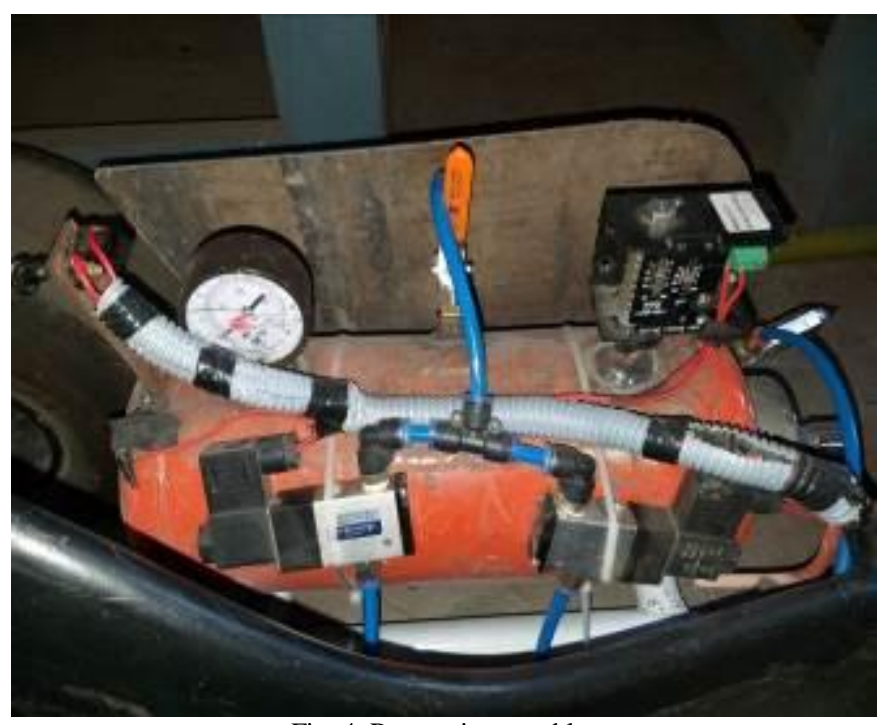

Fig. 4. Reservoir assembly.

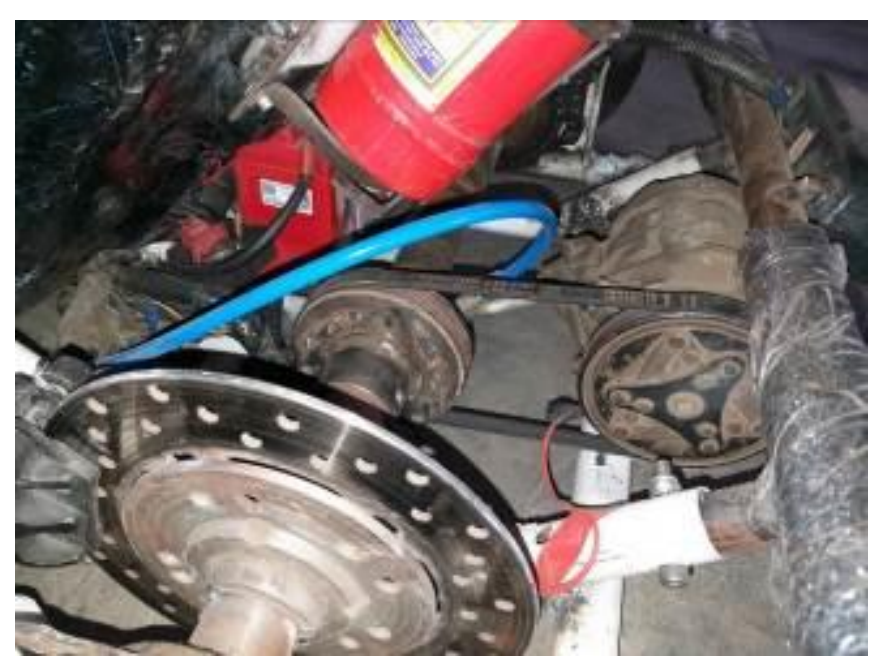

Fig. 5. Compressor mounting

\section{RESULTS AND DISCUSSIONS}

Weight being a crucial element in karting the whole pneumatic shifting assembly weighs around $7 \mathrm{~kg}$. The system was tested out on a race track and the performance counters the downside of the additional weight of the system. The shifting time has drastically reduced and multiple gears can be easily dropped while slowing down for entering a corner. The driver uses both hands for steering which has improved safety to a greater extent since the kart regularly keeps hitting triple digit speeds. Shifter karts usually have their engines mounted besides the driver which makes the weight distribution uneven. Therefore, the system is strategically mounted to reduce the weight distribution problem. Fig. 6. Shows the kart in which the system is implemented.

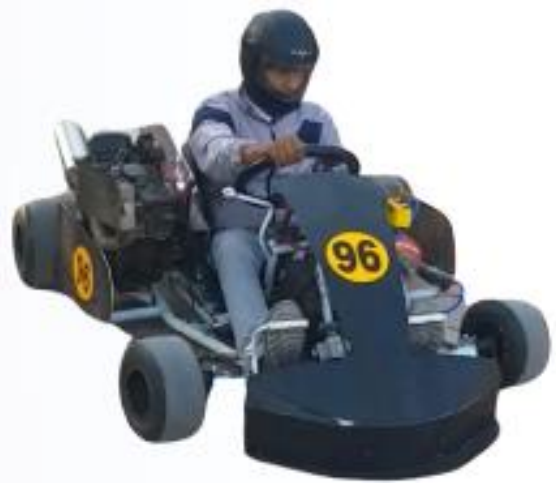

Fig. 6. Shifter kart.

Table 5 below shows comparison between manual and pneumatic shifting mechanism.

TABLE 5: comparison

\begin{tabular}{|l|c|c|c|}
\hline Sr.no & Parameter & Pneumatic & Manual \\
\hline 1 & Shifting time & $0.1 \mathrm{sec}$ & $>1 \mathrm{sec}$ \\
\hline 2 & Safety & maximum & minimum \\
\hline 3 & Weight & $7 \mathrm{~kg}$ & - \\
\hline 4 & Effort required & minimum & maximum \\
\hline 5 & Power consumption & $900 \mathrm{~W}$ & $0 \mathrm{~W}$ \\
\hline
\end{tabular}




\section{CONCLUSION}

The implementation of pneumatic system has improved the performance of the kart in terms of safety, lap times and weight distribution altogether. Since no electronics is used in the system it makes it quite robust to take the beating the kart usually goes through. The efficiency can be improved by introducing Pulse width signals to control the duration for which the DCV are operated

\section{REFERENCES}

[1] Lawrence, Don R. "Go-cart vehicle." (1990).

[2] Wadgaonkar, Tanmay J., Madhur R. Pawar, and Swapnil V. Vaidya. "Design and Manufacturing of Pneumatic Gear Shifter for GoKart." International Journal of Engineering Research \& Technology 5.8 (2016).

[3] Pawan R. Gurav, Rajesh M.Mhatre, Deepak B. Pal, Sahil R.Satvilkar, Geeta J. karmarkar. "Button Operated Gear Shifter in Two Wheeler using Stepper Motor.” International Journal of Scientific \& Engineering Research 8, no. 3 (2017).

[4] S. Vijay Kumar, P. Nithesh Reddy, P. Masoom basha. "Fabrication of pneumatic gear changer." IOSR Journal of Mechanical and Civil Engineering 11. no. 3 (2014)

[5] Mankar N.A, Keshar S. D, Minde R.R, Khaja Abulfaiz A. H, Barhe S. E. "Electro-pneumatic Gear Shifting Mechanism." International Research Journal of Engineering and Technology 3, no. 3 (2016).

[6] Shinde, Shravan Anil, and Pranit Narayan Nayyar. "Design of Arduino driven gearbox." (2019)

[7] DeJonge, Robert A., and Stephen D. Wexall. "External electronic transmission shift system." (2001).

[8] Dahiya, Siddharth, Adithya Asok Sharma, Rahul Srinivasan, Ritesh Tekriwal, Kamalkishore Vora, B. Ashok, and C. Kavitha. "Electropneumatic shifting system and gear control unit for a sequential gearbox."(2016).

[9] Suryavanshi, Kartik, and R. K. Tyagi. "Design and development of Electro-pneumatic gear shifting mechanism." 